\title{
EL NUEVO MERCURIO (1907) EN EL EJE ESPAÑA/FRANCIA/AMÉRICA
}

\author{
MARGARITA MERBILHAÁ \\ margaritamerbilhaa@yahoo.com \\ IdIHCS CONICET/UNLP
}

\section{Resumen}

Este trabajo se propone estudiar distintos aspectos tanto materiales como discursivos del programa editorial de El Nuevo Mercurio, la revista editada entre enero y diciembre de 1907 en Barcelona, y dirigida desde París por el escritor guatemalteco Enrique Gómez Carrillo. Intentará analizar las filiaciones trazadas por la publicación respecto de sus antecesoras, como también los vínculos que entabló con sus contemporáneas españolas. Con el propósito de indagar no sólo las ideas estéticas sostenidas en esta publicación sino también su relación con el contexto de debates en el que intervino, me detendré en los discursos inaugurales de la revista, y en otros modos en que desplegó una estrategia de autopromoción comercial mediante su enunciación directa a los lectores. A su vez, cuestiones materiales como su formato, financiación o composición interna me permitirán precisar los rasgos del locus de enunciación que la revista recortó al insertarse en el espacio español/latinoamericano de revistas literarias.

Palabras clave: El Nuevo Mercurio, Enrique Gómez Carrillo, modernismo, redes de latinoamericanos en europa, revistas culturales de comienzos del s.xx

\begin{abstract}
This article aims to study some material as well as discourse aspects of El Nuevo Mercurio publishing program. This review was directed from Paris by the Guatemalan writer Enrique Gómez Carrillo between January and December 1907. I attempt to analyze which filiations it has created in respect of its predecessors and also its links with other contemporary Spanish reviews. In order to inquire into not only the esthetics ideas developed by the review, but its connections with the context of discussions in which it took place, I will focus on its opening discourses, as well as other means of commercial self-promotion strategies through direct enunciation, that were addressed to the readers. Moreover, some material questions like its format, financial ways and
\end{abstract}

Anales, 26, 2014, pp. 287-308

DOI: 10.14198/ALEUA.2014.26.13 
internal composition may help to give details about the enunciation locus that was trimed by the review in its attempt to insert itself into the Spanish/Latin-american literary reviews field.

Keywords: El Nuevo Mercurio, Enrique Gómez Carrillo, modernism, latin-american nets in europe, beginnings of xxth century cultural reviews

El siguiente trabajo se propone estudiar distintos aspectos tanto materiales como discursivos del programa editorial de El Nuevo Mercurio, la revista editada entre enero y diciembre de 1907 en Barcelona, y dirigida desde París por el escritor guatemalteco Enrique Gómez Carrillo. Con el propósito de indagar no sólo las ideas estéticas sostenidas en esta publicación sino también su relación con el contexto de debates en el que intervino, prestaré especial atención a los discursos inaugurales de la revista, junto a otros modos en que desplegó su enunciación directa a los lectores. A su vez, cuestiones materiales como su formato, financiación o composición interna me permitirán precisar los rasgos del locus de enunciación que la revista recortó al insertarse en el espacio español/latinoamericano de revistas literarias (ya veremos de qué modo esta imprecisión geográfica es parte constitutiva de su identidad). En efecto, al existir ya revistas destinadas a los circuitos cultos de las principales ciudades de España, y también de Sudamérica, una de las preocupaciones centrales del director de El Nuevo Mercurio estuvo dada por su intento de asignarle un lugar específico dentro de las publicaciones ya existentes.

Comenzaré entonces por caracterizar la función del director y el tipo de relaciones de sociabilidad que puede reconstruirse a partir de algunas memorias y correspondencias, teniendo en cuenta los nombres que figuraban en los índices de cada número. Luego analizaré la intervención inicial de la revista dentro del espacio de publicaciones españolas. A partir de esto, intentaré dar cuenta de cómo se configuró una triangulación geográfico/cultural entre España, Francia y la «América española». Me baso aquí en el abordaje propuesto por Daphné de Marneffe (2007, págs. 43-46) quien a partir los trabajos de Prochasson (1993), define este tipo de artefacto cultural a partir de su doble dimensión de proyecto editorial periódico, es decir, en tanto «lugar» de edición; y, a su vez, en su dimensión «humana» colectiva, que la autora define en términos de «ámbito» de intercambios, materializado en la revista. A esta concepción de la revista como lugar («lieu») y ámbito («milieu»), Marneffe propone un tercer nivel de análisis, más allá del objeto revista, que está dado por la red o espacio contemporáneo de revistas en el que una publicación intenta insertarse. En otras palabras, se trata de identificar los vínculos entre 
ellas, a veces polémicos pero otras veces de solidaridad -tal como sucede en el caso de los campos literarios en formación-. ${ }^{1}$

Siguiendo este enfoque, me detendré en algunos rasgos del proyecto editorial que surgen del examen de su realidad textual, discursiva. Esto me llevará a considerar el proyecto editorial de El Nuevo Mercurio en relación con las condiciones de producción y circulación de las publicaciones periódicas bajo las cuales se desarrolló. También me permitirá establecer algunas líneas comunes de debate entre ésta y otras revistas, como la definición en torno a la literatura hispano/latinoamericana en su especificidad y a la vez como expresión particular de una universalidad de ideas y escritos; o el tratamiento de cuestiones no literarias, dentro de la revista, como es el caso de la participación de las repúblicas centro y sudamericanas en el ámbito de las relaciones internacionales, y sus efectos políticos y culturales.

\section{Inicios del proyecto y filiaciones}

Cuando dio lanzamiento a una nueva publicación dedicada a la literatura y otras novedades culturales de España y América Latina, Gómez Carrillo llevaba más de quince años viviendo en Europa y gozaba ya de cierto reconocimiento, alcanzado gracias a sus crónicas periódicas para La Nación y El Cojo Ilustrado, y otras publicaciones españolas y francesas (El imparcial, El liberal, Mercure de France, entre otras). ${ }^{2}$ La idea de publicar una revista destinada al

1. La autora considera que «es posible aplicar el término red a la modalidad lábil de este espacio [de revistas contemporáneas] al que hemos definido (en contraste con la noción de campo), como espacio sin demarcación (sino abierto y en constante reconfiguración), sin especificidad (híbrido, sin especialización), regido por una lógica de solidaridad (que federa a una colectividad) y en una relación problemática con la temporalidad (que requiere ser comprendida en la diacronía). (...) Siguiendo a Gisèle Sapiro, se la puede concebir como «semi-institucionalizada» en la medida en que las revistas resultan «más o menos efímeras» y poseen «contornos relativamente difusos» (al carecer de demarcación y de especificidad). Como hemos visto, esta red constituye una realidad compleja y en permanente reconfiguración» (Marneffe 2007, pág. 45).

2. Sobre el reconocimiento de Gómez Carrillo en España y Francia, véase el reciente trabajo de Jiménez Aguirre (2010, págs. 35-41). Además de su prolífica actividad como cronista literario y de viajes en diarios latinoamericanos, españoles y franceses y revistas como Mercure de France y, en España, Madrid Cómico, Vida Nueva, La Vida galante, La Vida literaria, Electra, Nuestro Tiempo o La Lectura (Cf. Celma Valero 1991), tal reconocimiento se explica por su trabajo para Garnier y por la frecuente edición de recopilaciones de crónicas. A esto se suman prácticas de sociabilidad más informales como su frecuentación de los cenáculos de La Plume, y de los cafés y restaurantes parisinos y también madrileños y el envío continuo por correspondencia de sus libros, a muchos pares. El periodista sevillano Rafael Cansinos Assens, quien dejó testimonio de ese reconocimiento: «A partir de 1900, todas las modas literarias de París fueron conocidas

Anales, 26, 2014, pp. 287-308 
ámbito español y latinoamericano provino de la Casa Editorial Sopena de Barcelona, con la que el director firmó un contrato de un año para editar un número mensual. ${ }^{3}$ Se editó en formato in-octavo, con tipografía Art Nouveau (moderna y parisina), buena calidad de papel, y el señalamiento de París como lugar de enunciación -y no de edición, pues se imprimía en Barcelona- que aparecía junto a la fecha, ya en el lomo del volumen. Esto último revela una voluntad de situar la revista ubicuamente, acaso como un modo de distinguirla. En efecto, esto permitía ubicarla en la «meca» literaria, aunque apareciera en castellano y se editara en España. Por lo demás, si el título connotaba, tal como veremos, su afrancesamiento, no dejaba de evocar el espacio latinoamericano puesto que, al menos entre los lectores letrados latinoamericanos, su nombre se acercaba mucho al de una de las publicaciones inaugurales del modernismo hispanomericano, El Mercurio de América.

Asimismo, la iniciativa comercial de los hermanos Sopena coincidía con otras estrategias de las casas editoriales francesas que, hacia la misma época, procuraron asociar la actividad de edición de libros con la publicación de revistas culturales, sobre todo de carácter general y destinadas a un público culto. ${ }^{4}$ Esto explica que la única publicidad de la revista fueran los anuncios sobre las próximas salidas de libros o colecciones de la Casa Editorial financiadora de la edición. La promesa de un número fijo de páginas, compiladas en base al criterio de la originalidad, evidencia además el carácter antológico que buscaba imprimirse al proyecto, tanto como su grado de especialidad (las artes, la literatura, el pensamiento, podría decirse).

Es probable que no sólo el renombre de Gómez Carrillo como cronista estrella en la prensa diaria de habla española y en la parisina a la vez, su intensa producción y su no menos activa vida social, hicieran de él la persona ideal

en España a través de las crónicas de Gómez Carrillo. La introducción de galicismos, palabras exóticas, el desdén por la Academia, se debían en gran parte a su influencia» (en Jiménez Aguirre 2010, pág. 40).

3. En el diario que llevaba la escritora peruana Aurora Cáceres, la primera esposa de Gómez Carrillo, durante el año que vivió con él (entre 1906 y 1907), encontramos algunas menciones a este proyecto, que confirman cierto carácter comercial de la empresa. En la entrada del 12 de octubre de 1906, escribe Aurora Cáceres: «Le entusiasma la idea de publicar un nuevo periódico, que tratará de los intereses de las Repúblicas de la América española. Ojalá le resulte algo práctico porque generalmente es tan iluso que da su trabajo y el prestigio de su nombre por las promesas que le hacen, y las utilidades las aprovechan otros» (Cáceres 2008, pág.158). El diario de la escritora también da cuenta de la intensa actividad intelectual y social de su esposo, a quien ayuda con la corrección de las galeras o la recepción de artículos cuando el tiempo lo apremia.

4. Mollier (2002, pág. 43-44) analiza la centralidad de las revistas en la estrategia de los editores franceses más relevantes de fines del siglo XIX, que buscaban menos una rentabilidad de la empresa en sí que de captación de un lectorado para sus libros. 
para dirigir la nueva publicación. Un dato no menor es que su principal medio de subsistencia lo constituía la actividad intelectual, que sin embargo no le alcanzaba para solventar sus gastos, de allí que completara sus ingresos con un cargo diplomático en representación de Guatemala en Alemania, situación común a los latinoamericanos que circulaban por Europa a comienzos del siglo XX. ${ }^{5}$ Es la necesidad económica, tal como se desprende del diario de quien era por entonces su esposa, la escritora peruana Aurora Cáceres, la que lo llevó a aceptar el contrato ofrecido por Sopena. ${ }^{6}$ Ya veremos, en este sentido, que la promoción comercial de la revista resulta muy visible, empezando por el anuncio del precio impreso en la tapa ( 4 REALES»), de manera muy legible. Este aparecía resaltado en negrita, con la moneda en versalita y subrayado doble, y ubicado exactamente debajo del sumario, en la última línea, en el ángulo inferior derecho.

Con respecto a la dimensión social de la revista, ni en el diario de Aurora Cáceres, ni en las cartas que ella copió allí, ni en los epistolarios de Rubén Darío (1940; 1999), Manuel Ugarte (1999) o Unamuno ${ }^{7}$ se hace mención de

5. Cf. Molloy (1972); Merbilhaá (2013).

6. En el diario que publicó por primera vez en 1929, a dos años de la muerte del escritor, y veinte después de su separación, Aurora Cáceres transcribe también algunas cartas de su por entonces esposo. Así nos enteramos de los intentos de Gómez Carrillo por conseguir, a través de ella, un cargo de Encargado de negocios en Alemania para representar al Perú, para conseguir luego un Consulado de ese país, en caso de necesidad; conocemos su trabajo diario de corrección de galeras para los editores de sus libros, o de las pruebas del primer número de El Nuevo Mercurio, y también de sus apremios económicos: «Así quedan pagados tus 400 francos y no te deberé sino 30 por el cambio -le dice en otra carta de noviembre de 1906-. ¿Te he dicho que estoy en la mayor miseria? No sé cómo voy a hacer con mi Canciller aquí, y el hotel, y el coche y el diablo. En fin, más tarde se verá...» (Cáceres 2008, pág. 198). Encontramos así un valioso testimonio sobre los aspectos materiales de la vida de un escritor latinoamericano a comienzos de siglo en Europa: en medio de la decisión de separarse, en marzo de 1907, Gómez Carrillo le ofrece «lo necesario para que vivas -dice- en Lima con tu madre o en Roma con tu padre, y mientras mis ocupaciones consulares me den con qué hacerlo. Ahora, el día que se trate de vivir sólo de mi pluma, como tú ya sabes lo duro que eso es, tendremos que separar nuestra existencia» (Cáceres 2008, pág. 222).

7. Una carta sin fecha de Gómez Carrillo a Unamuno, conservada en la Casa Museo del rector de la Universidad de Salamanca (cf. Bibliografía), ofrece una prueba del carácter individual del emprendimiento, y confirma además, la solicitud de colaborar gratuitamente con un artículo para la revista. Vale la pena transcribir la carta completa, pues contiene valiosos datos acerca de las formas concretas del trabajo intelectual y en particular, sus aspectos económicos:

«Mi querido maestro. Como yo también soy un apasionado bajo mi capa ligera, me he decidido a publicar una revista mensual, cuyo título le indicará a V. la índole: El Nuevo Mercurio. Por ahora apenas hay dinero para pagar al impresor, pero espero que dentro de seis meses las Américas, en donde según dicen mi nombre se cotiza caro, me darán con qué pagar también a los escritores, y entonces tendré el gusto de pedir a V. para cada 
alguna modalidad de organización grupal de la revista. Sólo se nombran el contrato con los Sopena (en las primeras), las invitaciones a colaborar en ella, la recepción de artículos o de sus pruebas para corregir, y el anuncio de la salida de un nuevo número. Al parecer, Gómez Carrillo centralizaba todas las tareas editoriales y de compaginación, y sólo se apoyaba en su esposa, que colaboraba con las correcciones, envíos y recepción de correspondencia. Como veremos, esta centralidad del director también se verifica en otros aspectos editoriales de la revista.

Si se examina el índice del primer número, resulta evidente que, durante la preparación de la revista, Gómez Carrillo había recurrido a su propio capital social, conseguido durante sus estancias en Madrid y en su residencia en París, y lo había reinvertido pidiendo colaboraciones para la revista a los amigos escritores o conocidos (sin ofrecerles paga alguna): además de Unamuno, en ese primer volumen hicieron su aporte de artículos, poemas o ficciones Rubén Darío, Jean Moréas (a quien el director conocía de los dîners de La Plume, y con quien cenaba cada tanto -Cáceres, 2005), Max Nordau, cronistas franceses más o menos famosos como los hermanos Paul y Victor Margueritte, o Pierre Louys, y sus amigos españoles Andrés González Blanco y Gregorio Martínez Sierra. A esto se sumaron los recursos literarios del propio Gómez Carrillo, en éste y en casi todos los números siguientes, con la publicación de varias crónicas y adelantos de sus últimos libros. ${ }^{8}$

número un artículo sobre las novedades literarias españolas. Mi rêve sería que V. hiciera ahí una sección fija: Letras españolas. Pero de esto hablaremos cuando sea tiempo. Entre tanto lo que le ofrezco a V. es la revista para que V. diga en ella lo que quiera, como quiera. Y lo que le pido, para que me la mande a vuelta de correo, es algún artículo suyo antiguo y poco conocido, para poder darlo como inédito. Con que V. le ponga cuatro líneas de encabezamiento hablando del Nuevo Mercurio, bastará para que lo tomen como cosa nueva. Los pobres tenemos que saber el arte de arreglar los restos. ¿Ha visto V. la colaboración que he contratado para El Imparcial? Hasta a Tolstoy les he conseguido. Ojalá me mande V. algo relativo a letras americanas en general, algo halagador, como todo lo que V., cuando se trata de América en general. Ya sabe V. que le quiere y admira su amigo, Gómez Carrillo. 1, Square Alboni».

8. Aparte de las notas de presentación y cierre de la revista, aparecieron colaboraciones de Gómez Carrillo que retomaban los temas que se encontraba escribiendo, como el de sus viajes a Japón, por un lado, en los números 1 y 4, anticipos de El alma japonesa y Terres lointaines, el primero reeditado y el segundo publicado en 1907 y, por el otro, África del Norte (n. ${ }^{\circ}$ 9). Además, en el número 5 , aparece la reproducción de su artículo sobre su propia revista, para la Sección «Lettres espagnoles» del Mercure de France, que comentaré más adelante. Otros artículos fueron escritos especialmente para la publicación: «Los progresos artísticos de Buenos Aires (n. ${ }^{\circ}$ 2) o «Crónica de primavera» (n. ${ }^{\circ}$ 7). Estas autorreferencias se completan con la reproducción de artículos críticos sobre sus obras, publicados previamente en revistas parisinas (de Émile Faguet y Catulle Mendès en los números 3 y 7 ). 
La existencia de un contrato quizá explique el cuidado puesto en la preparación de cada número, y su grado de programación. Ya en la tapa se prometían «120 páginas de texto inédito», lo que da cuenta además, de la planificación de cada volumen. Así, por ejemplo, en una carta del director a su esposa, éste le indica que un artículo de Mitty, llegado mientras se encontraba fuera de París cumpliendo con sus obligaciones de diplomático en Alemania, era para la revista y no para El Imparcial. ${ }^{9}$ A su vez, por el diario de Aurora Cáceres, también sabemos que él había pedido a Darío una respuesta para su encuesta sobre el modernismo, antes mismo de que apareciera el primer número, puesto que la respuesta negativa del nicaragüense le llega en una carta de enero de 1907. Otros rasgos de la revista indican el cuidado en su preparación, incluso antes de que saliera por primera vez. Esta rigurosidad, o el carácter no diletante que se buscaba otorgar a la revista hicieron que, por ejemplo, los próximos colaboradores fueran anunciados en las notas a pie de página, o que se incluyera después del título de la mayoría de los artículos, una nota con la leyenda: «(Para EL NUEVO MERCURIO)». En el mismo sentido, la revista prometía que «Pierre Jan nos dará para cada número un artículo sobre los asuntos palpitantes de arte» (El Nuevo Mercurio, 1, pág. 24), o nuevas colaboraciones de un mismo autor.

Otro aspecto que evidencia el esmero de la revista por ofrecer un producto serio, reside en la formalidad de la nota de «Advertencia» referida a la recepción de los manuscritos, que figuraba en la contraportada del primer número:

Siguiendo el ejemplo del Mercure de France, El Nuevo Mercurio establece un Consejo de Redacción al cual se someterán los originales que se reciban y que no hayan sido pedidos especialmente por el director. Esta junta, compuesta de tres personas cuyos nombres quedarán secretos, aceptará los trabajos que le gusten y destruirá los que crea deber rechazar...» (El Nuevo Mercurio, 1 y ss.)

Resulta significativo que la «Advertencia» sobre la política de evaluación de los artículos fuera la única mención de un equipo editorial. En efecto, en la tapa y la contraportada, el único nombre que figuraba era el de su director,

9. A fines de noviembre de 1906, Aurora Cáceres escribe en su diario que su esposo ha tenido que viajar a Alemania (donde tiene el cargo de Ministro de Guatemala) y ella ha quedado a cargo de su correspondencia que «[la] tiene muy ocupada: tengo que revisar los paquetes de diarios y de revistas que llegan de todas partes, leer sus cartas por si contienen algo urgente, para comunicárselo y, además, corregir las pruebas que llegan de la imprenta» (Cáceres 2008, pág. 191). También transcribe sus cartas en el diario, con muchas instrucciones para reemplazarlo en sus tareas intelectuales: «El artículo de Mitty es para Nuevo Mercurio, no para El Imparcial. Guarda todo; todo lo que sean artículos» (págs. 198-200).

Anales, 26, 2014, pp. 287-308 
omitiéndose el de cualquier otro integrante. Esto prueba la casi exclusiva intervención del director, a la que me he referido más arriba. Por lo demás, la práctica de selección de manuscritos parece no haberse concretado si se tiene en cuenta que en ninguno de los números se menciona la inclusión de un artículo publicado luego de este proceso de selección. En cambio, la nota aclaratoria, citada más arriba, encabezaba la mayoría de los artículos, después del título. De modo que parece más bien haber predominado el encargo del director. Más aún, tal «Advertencia» sobre la política editorial se contradecía en otro anuncio, esta vez, en las contratapas de los números siguientes al primero, que rezaba:

EL NUEVO MERCURIO. REVISTA MENSUAL DE LITERATURA, ARTES, ESTUDIOS SOCIALES, ETC.

Todos los trabajos que publica son escritos expresamente para la revista, salvo las excepciones que se indican en el texto mismo. (El Nuevo Mercurio, 2 y ss.)

Un último aspecto que también es revelador de la planificación y el cuidado puestos en la oferta editorial, está dado por la regularidad de los sumarios, de uno a otro número. Impresos en la tapa, cada uno de ellos estaba compuesto por el índice de autores, el título de cada artículo con la página correspondiente y, en la última línea, una misma sección titulada «Variedades y revista de revistas y periódicos» con la letra «X» en el lugar del autor: se trataba de una miscelánea de noticias, sueltos transcriptos de otros periódicos ( $\mathrm{La}$ Nación, Studio, La Revue, New York Journal), reseñas de críticas sobre obras teatrales, arte o literatura, o novedades editoriales. ${ }^{10}$

Esta sección fue ocupando cada vez más páginas a medida que salían nuevos números y por supuesto, Gómez Carrillo era quien estaba a cargo de su composición. Así se entiende que la sección fuera presentada especialmente, en el número 1:

En esta sección [Variedades y revista de revistas y periódicos], que será una de las más interesantes como documento universal, daremos cada mes un reflejo de la producción intelectual y del movimiento de las ideas en el mundo entero» (El Nuevo Mercurio, 1).

En esta sección, también se concreta la autopromoción (comercial) de la revista a través de la reproducción completa de artículos referidos a ella, aparecidos

10. Por ejemplo, una breve nota titulada «Notas yanquis de Gorki», sobre la salida de un libro del escritor ruso sobre los Estados Unidos, en el número 8 (págs. 947-949). En la página siguiente, otra nota lleva el enigmático título de «La belleza argentina» que comienza así: «El Jornal del Brasil publica lo siguiente: 'La Argentina no es un hermoso país...» (n. ${ }^{\circ} 8$, pág. 950). 
en otras publicaciones como el Mercure de France, La Época y La Nación. Precisamente, dicha autopromoción se continuaba en «Variedades...», que concentraba la interpelación a los lectores. Algunas veces se trataba de mínimas intervenciones interpuestas en medio de un artículo, mientras que en otras, la estrategia de autopromoción era explícita, o remitía al propio director. Quien asumía la enunciación era un «nosotros», pero el plural parece más bien una formalidad si lo confrontamos tanto con las cartas transcriptas por Aurora Cáceres en su diario, como con los epistolarios antes mencionados, en los que resulta claro que la organización de la revista dependía de su director. Lo cierto es que la revista explicitaba a menudo su punto de enunciación, y se dirigía a los lectores como pares. Esta interpelación directa, además de responder a una retórica de autopromoción de los artículos y colaboradores, hizo posible que la revista estuviera continuamente referida, como si se buscara exhibir a los lectores las marcas mismas del proceso de elaboración del material que se les ofrecía (lo que indirectamente remitía, otra vez, a su director).

De este modo, la noticia sobre la visita del historiador Gugliermo Ferrero a Argentina, por ejemplo, se informaba sin ningún desarrollo sobre el evento en sí; pero significativamente, era la ocasión para introducir una voz en primera persona cuya identidad no se explicitaba, como si fuera natural inferir el sujeto de dicha enunciación: «Permitid que recuerde hoy una conversación que tuve con él [Ferrero] hace poco en Milán. La reproduzco tal cual está en mi libro de memorias...» (El Nuevo Mercurio, 9, pág. 1070). Esta modalidad de intervención también se advierte en el hecho de que, a lo largo de cada número, los materiales seleccionados se presentaban con las marcas de la práctica de compaginación, en una suerte de mediación entre los autores publicados y los lectores. De este modo, Gómez Carrillo intervenía como articulador (implícito y -a veces- explícito) de esas voces, cumpliendo simbólicamente una función de guía de lectura dentro del intrincado mundo de las ideas y las artes, que los jóvenes escritores se representaban como en continuo cambio...

Esta función de guía también está presente en las encuestas. Precisamente, en ellas los diferentes escritores eran convocados por un observador que hacía las preguntas necesarias para el diagnóstico que se les requería. Así, se ofrecía una puesta a punto, un balance de tendencias del presente pero los primeros sentidos seleccionados ya estaban presentes en los temas y preguntas elegidos para la encuesta. Esto explica a su vez la centralidad que tuvo el recurso de las encuestas dentro de las estrategias de interpelación de la revista pues, en apenas doce números, además de la encuesta sobre el modernismo se realizó otra que inquiría a distintos escritores franceses, sobre su conocimiento de España. 
De este modo, en la sección sobre las «Variedades y revista de revistas y periódicos» se concretaba el objetivo de registrar las novedades de la producción artística, literaria e intelectual del mundo contemporáneo, en su estado «palpitante», de allí que presentara actualidades artísticas tanto parisinas como latinoamericanas y españolas. En nombre del cosmopolitismo -para decirlo en los términos de la época-, esta perspectiva se ubicaba, así, por encima de las fronteras nacionales. La consecuencia en términos de la circulación de la ideas que vehiculizaba la revista, iba en el sentido de una construcción de universalidad que por, lo que se ve, no respondía sólo a las intenciones de su director sino que de hecho, como efecto de lectura, igualaba en la propia compaginación de la revista, todas las manifestaciones culturales más allá de las fronteras geopolíticas, dentro de lo que se percibía como un orden mundial de las ideas y prácticas artísticas.

A partir del número 5 , se incrementó mucho la cantidad de páginas de la sección (de cuatro en el primer número, a dieciocho en el quinto), lo que hace presumir un intento de compensar la dificultad para conseguir contribuciones no remuneradas (recordemos que el objetivo de la publicación, anunciado en la tapa era la publicación de escritos inéditos), con un mayor trabajo de edición del material de la revista, a cargo del director. Su trabajo se verifica, tal como venimos analizando, en las numerosas intervenciones en primera persona que iban hilvanando las noticias de la sección, referidas a la actividad intelectual y editorial que se seleccionaban para volver a ser difundidas y articuladas en el cuerpo de la revista. ${ }^{11}$

Sin embargo, el proyecto no rindió los frutos esperados, situación que culminó en el cierre de la revista, en diciembre de 1907, número en el que se exponen los motivos financieros que determinaron tal decisión. Ya en abril de ese mismo año, apenas cuatro meses después de iniciada la publicación, el balance del emprendimiento no parecía dar un saldo positivo. Así exponía por carta Gómez Carrillo, en medio de su separación de Aurora Cáceres, las razones que le impedían dejarle su domicilio (en el 1 Square Alboni, el mismo que figura como sede de la Revista): «a pesar de mis labores, que se agravan con un artículo por semana para El Imparcial, me es imposible, a causa de mi

11. Esta particular intervención de la revista ha sido recientemente señalada por Jiménez Aguirre (2010): «La participación del lector en El Nuevo Mercurio fue convocada desde el primer número; a lo largo de los once siguientes el director apeló al público por medio de un sistema novedoso y original de comentarios personales, apostillas y avisos editoriales al final de la mayoría de las colaboraciones. En el ámbito hispanoamericano, debe considerarse a Gómez Carrillo como el fundador de este género de marginalia editorial» (pág. 48). 
ruinoso contrato con Sopena, dejar la casa antes del $1 .^{\circ}$ de febrero de 1908» (Cáceres 2008, pág. 245), es decir al cumplirse un año de la firma del contrato de edición de la revista.

Sin duda, las memorias y correspondencias nos permiten precisar datos y confirman que la presencia de los latinoamericanos en Europa respondió también, y más allá del deseo de París, a necesidades profesionales concretas. Podría decirse, en este sentido que el deseo de París, no era otra cosa que el deseo de trabajar en París para vivir de su pluma. De hecho, el proyecto de la revista se explica en el marco de una necesidad laboral de su director que, más allá de la legitimación de los pares y de desplegar el tópico del desinterés, hacía depender su éxito del consumo de los lectores, tal como leemos en las palabras del cierre de la revista. Así, mientras celebraba la «atención literaria» de que gozó la revista, agregaba:

Mas, por desgracia, el entusiasmo de los aficionados no basta para hacer vivir una empresa que representa un verdadero capital.

Dios sabe sin embargo que ni el editor ni el director pensaron jamás en ganar dinero con «El Nuevo Mercurio». Lo único que esperaban, disponiendo como disponían de la colaboración enteramente desinteresada de los más eminentes escritores de Europa, era que los lectores produjeran lo necesario para los gastos materiales de la impresión y del correo. Ni esto hemos logrado.

(...) Pero no hemos conseguido el número de suscriptores que para vivir necesitábamos (págs. 1324-1325)

Ahora bien, entre las causas que llevaron al cierre de la publicación, quizá haya que considerar también el carácter individual que tuvo el desarrollo del proyecto, del que he intentado dar cuenta.

El primer número de El Nuevo Mercurio había salido en enero de 1907. Apenas dos meses después, Enrique Gómez Carrillo presentaba la nueva publicación a los lectores franceses en la sección «Letras españolas» del Mercure de France, que él mismo tenía a su cargo. En esta presentación, sin embargo, soslayaba un detalle no menor, pues no mencionaba su propio vínculo -por cierto estrecho- con la revista. Al omitir el nombre del director de la publicación a la que estaba dedicada la ya mencionada sección del Mercure de France, el cronista no sólo disimulaba el «autobombo», sino que procuraba evaluar la revista a través de una enunciación distanciada. De ese modo, podía establecer filiaciones que colocaban la revista en un lugar encumbrado dentro de una serie preexistente de manifestaciones culturales novedosas. En efecto, la crónica del Mercure de France se iniciaba insertando a la nueva publicación dentro 
una supuesta tradición de muchos «mercurios», «de todos los colores», que habían aparecido en «lengua española» (subrayemos: no meramente en América) y que de entrada se habían vinculado con las novedades estéticas de la revista francesa, por influencia de ésta (Gómez Carrillo 1907a, pág. 180). ${ }^{12}$ Entre tantos emprendimientos, a los que consideraba «todos efímeros» el cronista destacaba uno que según él merecía ser recordado:

Sin embargo, hubo uno que entre ellos, por su importancia e influencia, habría merecido una larga vida. Me refiero al Mercurio de América, de Buenos Aires, que por imitación del Mercure de France fundó un grupo de jóvenes escritores. En la forma, la división de las secciones, los temas y aun las letras de imprenta era idéntico a la revista francesa...

El conjunto era muy interesante. Pero el público de Buenos Aires, que enriquece a los fundadores de semanarios del tipo de la Risa, no prestó su apoyo a la pléyade «modernista», y así murió el Mercurio de América.

La idea, sin embargo, se mantuvo viva. De un lado a otro del imperio de nuestra lengua, es decir desde San Sebastián hasta México, y de Sevilla a Chile, los jóvenes siguieron creyendo que una revista española, semejante en su naturaleza al Mercure de France, era necesaria (Gómez Carrillo 1907a, págs. 180-181).

Así, el cronista establecía un lazo de filiación con la revista porteña dirigida por Eugenio Díaz Romero de 1898 a 1900, y mencionada en este fragmento, al evaluar esa experiencia en términos de un «conjunto interesante». Enseguida destacaba que pese al cese de la publicación, la «idea» se había «mantenido viva». La nueva revista venía entonces a asentarse sobre esa pervivencia. Este gesto se mentaba desde el título de la revista (un «nuevo» Mercurio), en términos de otro intento más, una insistencia renovada dentro de una continuidad que su antecesora habría inaugurado.

Ahora bien, si Gómez Carrillo situaba de hecho a la revista en esa tradición modernizadora nacida en América, se cuidaba especialmente de destacar este origen hispanoamericano, y prefería hablar de «los mercurios que han existido siempre en la lengua española», omitiendo de este modo su origen subcontinental. Esta ampliación de fronteras, que iba trazando una triangulación geográfico/cultural entre España, América y Francia, se completaba con el intento del director de la revista, de ubicarla con mucha precisión dentro del espacio de las revistas españolas existentes, para delimitar allí un lugar

12. La traducción de este artículo es mía. Aquí posiblemente Gómez Carrillo se estuviera refiriendo a otras revistas aparecidas también en el continente americano como las mexicanas Revista Azul (1894-1896), de Manuel Gutiérrez Nájera y Revista Moderna (1898-1903) que dirigía Jesús Valenzuela (García Morales 2010; Jiménez Aguirre 2012, pág. 45). 
vacante. La crónica de la sección del Mercure de France, a la que me vengo refiriendo, muestra ese gesto de manera elocuente: en ella el cronista destaca la modernidad alcanzada a ambos lados del Atlántico en materia de prensa periódica y semanarios ilustrados (cuyos nombres se encarga de difundir para los lectores franceses), que estaban a la altura «de nuestra época y nuestros progresos», para contraponer ese progreso a la inexistencia de «revistas dignas del siglo XX». Y va aun más allá en sus argumentos, al detenerse en las distintas revistas que en España, ocupaban los circuitos de publicaciones letradas específicas, es decir, distintas de los diarios o semanarios: La España Moderna (de José Lázaro), La lectura (de Francisco Acébal), Nuestro Tiempo (de Salvador Canals), Ateneo Científico, Literario y Artístico de Madrid (de Mariano Miguel de Val).

Buen conocedor de las distintas posiciones que cada una ocupaba en el espacio de revistas «cultas», Gómez Carrillo procuró distinguir a la suya respecto de las demás en dos aspectos: en primer lugar, en el orden estético, por considerar que éstas atrasaban «medio siglo» en materia de difusión de los movimientos literarios de una época. Además, afirmaba que había llegado la hora de admitir el «cambio completo [en] los gustos literarios, [luego de] la pesadez del naturalismo» (Gómez Carrillo 1907b, pág. 577). Probablemente se refiriera al hecho de que ni La España Moderna ni La lectura, sus posibles competidoras, pese a su rol modernizador de los debates de la vida intelectual en España (Serrano 2002, pág. 388), publicaran poesía sino traducciones de novelas (y reseñas de literatura realista y naturalista en el caso de $\mathrm{La}$ Lectura). ${ }^{13}$ Lo interesante es que esta comparación de Gómez Carrillo con las dos primeras revistas pone en evidencia su aspiración de convertir El Nuevo Mercurio en un difusor cultural amplio o generalista, no del todo restringido a las capillas literarias, aunque sí más innovador en materia de gusto estético. El segundo aspecto en el que Gómez Carrillo se distancia de las posiciones ocupadas por las demás revistas a las que menciona en su crónica era la, a su juicio, exclusiva atención que éstas atribuían a temas «de erudición o de sociología» (Gómez Carrillo 1907b, pág. 577). Su revista vendría entonces a revertir este defecto o falta, difundiendo las novedades y debates artísticos y literarios más recientes.

Tal recorte preciso de la posición que el director pretendía para su revista se completa, más adelante en la misma crónica francesa de marzo de 1907, con una última distinción respecto de dos publicaciones del pasado, La Revista de

13. Ahora bien, como afirma Carlos Serrano (2002, pág. 389), esto no impidió que la política editorial de ambas revistas fuera decisiva respecto de la difusión de la literatura extranjera, como por ejemplo la novela rusa o el teatro escandinavo. 
América y de Helios (de Juan Ramón Jiménez) con quienes compartía afinidades estéticas. Esta vez, el cronista enfatizaba la «llana imitación» del modelo francés del Mercure que las caracterizaba, y defendía la necesidad de superar esa tendencia. De este modo, más allá de las coincidencias estéticas con ambas publicaciones que, por lo demás, habían dejado de existir, la revista pretendía ahora completar el vacío dado por las simples imitaciones del modelo francés, sin dejar de reinvindicarlo. Al mismo tiempo, retomaba en sus páginas uno de los tópicos más transitados del período, el debate entre «viejos» $\mathrm{y}$ «jóvenes»; o el rechazo del galicismo mental versus la defensa del cosmopolitismo. Pero sobre todo, dicha superación era presentada como una necesidad colectiva del propio ámbito intelectual español. Cabe observar que aquí Gómez Carrillo omitía una vez más mencionar los espacios culturales de su continente de origen, y optaba en cambio por referirse a un área cultural que aparecía unificada exclusivamente en torno a la lengua común, y concebida por encima de las divisiones geopolíticas. De paso, el escritor evitaba referirse a otro tipo de lazos históricos más discutibles (entre España y América), o incluso al tópico del latinismo, que circulaba más bien en el ámbito francés. Cabe recordar que precisamente, la misma sospecha frente a dicho tópico había sido expresada por Unamuno en su primera colaboración para El Nuevo Mercurio:

Algún día he de decir por extenso todos los recelos que abrigo contra la literatura francesa y cómo bajo esa tan cacareada hermandad latina he sospechado siempre una hegemonía francesa. Y la verdad no hay cosas más opuestas entre sí que el genio español y el italiano de una parte, y el genio, o mejor el ingenio francés (Unamuno 1907, pág. 12).

Ahora bien, en los términos de la misma revista, su filiación intelectual con el mundo cultural francés y al mismo tiempo, la idea de que su aparición constituía una necesidad de los países de habla española, sin distinciones continentales, se advierten en la breve presentación del mismo número 1, «Dos palabras al lector», que lleva la firma de «El Nuevo Mercurio». En esta exposición de propósitos, la revista afirmaba que

La idea de esta revista no es nuestra. Es de todos los intelectuales serios de España y América. En la charla diaria, cada vez que se trata del Mercure de France, nuestros compañeros exclaman:

-Así debiera existir una revista en castellano.

Hela aquí. Su programa es muy sencillo y se reduce a lo siguiente: Establecer un lazo fraternal entre los intelectuales de España y los de la América española, que hasta ahora han vivido no sólo desconociéndose, sino hasta desdeñándose. Desdeñándose, sí (El Nuevo Mercurio 1, 1907, pág. 3).

Sin lugar a dudas, el declarado vínculo con Francia y la inclusión del artículo de Unamuno contribuían a atraer las miradas sobre la revista. Así, la revista 
explotaba este recurso al incluir en su número inaugural una colaboración de Unamuno que le estaba especialmente dedicada, en la que el escritor reeditaba su ataque a lo que allí nombraba como su «manía misogálica». Es más, no resulta casual que el único tono panfletario que aparecía en las palabras inaugurales fuera aquél dirigido contra el profesor de Salamanca, mientras que el manifiesto inicial se cuidaba de expresar cualquier esbozo de polémica contra, por caso, los miembros de la misma generación que el director de la revista.

De este modo, la revista se autopromocionaba actualizando el debate en torno a la ruptura del movimiento modernista con la tradición lírica española y su adhesión a las corrientes renovadoras francesas. Para ello invitaba a su principal cuestionador, Unamuno, al tiempo que tejía solidaridades con otros intelectuales españoles contemporáneos del director. Estos acercamientos pueden verse en la crónica sobre El Nuevo Mercurio aparecida en el Mercure de France de marzo de 1907, antes mencionada, y reproducida luego en sus mismas páginas, esta vez en traducción castellana, en el número 5. Allí el cronista (y director de la publicación) se refería, no casualmente, a varios directores de revistas españolas, como es el caso de Francisco Acebal, director de La Lectura, de quien transcribía un comentario referido a la falta de un Mercure de France para el público español:

Los propios directores de las más importantes publicaciones mensuales comparten esta opinión. El Sr. Acebal, director de La Lectura de Madrid, me dijo un día: «Lo que resulta indispensable es la creación de una revista como el Mercure de France. Pero no existen ni los elementos ni el entusiasmo... (Mercure de France, 1907, pág. 181)

Recordemos que en esta crónica de presentación de El Nuevo Mercurio a los lectores franceses (e hispanomericanos, lectores del Mercure), Gómez Carrillo se proponía colmar una supuesta necesidad colectiva de «revista literaria» y a su vez lograba definir el lugar preciso de la recién llegada publicación. Sin insistir en las diferencias respecto de sus pares contemporáneas, no dejaba de delinear para la suya una nueva identidad, marcando, significativamente, ciertas diferencias respecto de su antecesora americana. ${ }^{14}$

14. Este tipo de estrategia de solidaridad o mutua ayuda es precisamente la misma que destacó Marneffe para el caso de las revistas del joven campo literario belga, hacia los años 1920.

Anales, 26, 2014, pp. 287-308 


\section{Una invención de universalidad}

Para precisar el programa de la revista, señalemos sintéticamente los cuatro aspectos en que se desplegaron tales diferenciaciones: la superación de una etapa imitativa de los modelos europeos; una mayor diversidad de las ideas estéticas que circulaban dentro de la revista; la intención de incluir temas de actualidad no estrictamente literarios; por último, su extensión de las temáticas más allá de las fronteras latinoamericanas, hacia España e, incluso, Francia.

La insistencia en superar la imitación de modelos había caracterizado, según el cronista, el vínculo entre las revistas anteriores y el Mercure de France. Así, en la crónica de la sección del Mercure de France, reproducida como ya he señalado, en el número 5 de la propia publicación, se subrayaba una diferencia respecto del Mercurio de América, al argumentar que no debía ahora imitarse el color de la tapa, ni la tipografía, las secciones o algún género, como había hecho esa revista respecto de su modelo francés. En contraste, lo único que El Nuevo Mercurio tenía en común con la revista de los simbolistas franceses era señalado en términos de un valor compartido de orden muy general, o ethos común dado por su idéntico interés por la novedad y el cosmopolitismo.

Resulta interesante destacar aquí que Gómez Carrillo ofrece una percepción espontánea respecto del Mercure, que registra dos rasgos que han sido señalados por la crítica francesa como claves del éxito de esa publicación. En efecto, entre las numerosas revistas simbolistas aparecidas en la década de 1890 en Francia, el Mercure fue la única que logró perdurar, lo que fue posible gracias a su reconversión de su carácter de revista/antología, al de revista de difusión de la actualidad cultural. Michel Décaudin (1992) ha mostrado que al crear la sección «Revista del mes» y luego, al volverse quincenal a partir de 1905 y diversificar las secciones según las distintas actividades artísticas y las letras de diferentes países, la revista de Vallette pudo convertirse en una publicación de «amplia información cultural». ${ }^{15}$ Esta apuesta por la difusión de las novedades literarias incidió sin duda en la excepcional apertura

15. Michel Décaudin (1992, pág.14). El autor afirma que a partir de 1896, este cambio se vio acompañado por un abandono de la polémica literaria: «Los artículos críticos y eruditos, de información amplia y de actualidad, pasaron a ocupar la mayor parte de los índices» (pág. 14). De este modo, el Mercure de France presentaba un panorama sobre la actualidad cultural francesa e internacional y fue percibida por sus contemporáneos como la unión exitosa entre el periódico y el libro antológico, que así «se convirtió en una amplia revista enciclopédica. Vallette salvó su emprendimiento al saber darle una vuelta de página» (1992, pág. 15). 
«comparatista» (Jouanny 1992:56) desarrollada en la revista, que la llevó a incorporar otras actualidades literarias ajenas al ámbito francés. ${ }^{16}$

Como ya he señalado, además de hacer propia la difusión cultural, como así también esta apertura cosmopolita a las novedades, El Nuevo Mercurio incorporó otra característica del Mercure de France ${ }^{17}$ al incluir entre sus páginas a una diversidad de voces, susceptibles de interesar a una mayor amplitud de lectores, antes que ceñirse a una doctrina estética o acoger en su seno distintas querellas literarias.

Precisamente, el segundo gesto de diferenciación de la revista respecto de la tradición, surgida en América, de revistas modernizadoras, estuvo dado por su alejamiento de toda intención panfletaria, de sostenimiento de un manifiesto estético único. Ésta respondió, además, a una estrategia de intervención en el mercado de las publicaciones para el «público letrado» (Gómez Carrillo 1907b, pág. 581), que no sólo buscó una cierta diversidad temática, sino también incluir voces contrarias a las ideas estéticas modernistas a las que, sin embargo, adhería, como se desprende de los poemas que eran seleccionados y antologados a lo largo de sus números. Entonces, además del artículo de Unamuno que retomaba sus críticas antirrenovadoras (por antigalicistas), también publicó otros dos de Max Nordau. El primero repetía sus ideas sobre la degeneración de las «razas humanas» y en el segundo, dedicado a «El modernismo en España y América» (n. ${ }^{\circ}$ 3), el autor impugnaba la falta de originalidad de dicha escuela y la explicaba por la tendencia a la «importación de modelos franceses que ya no están de moda en Francia» (pág. 243). Por otro lado, cuando el periodista argentino Guillermo Paterson, en un artículo publicado en La Nación (bajo el seudónimo Pater) y que la revista reproducía en el número 8, celebraba la aparición de El Nuevo Mercurio, era por su

16. Robert Jouanny (1992, pág. 58) ha señalado que dicha apertura hacia las producciones literarias europeas no dejó de responder a un insoslayable «egocentrismo» francés. En sus comienzos, entre 1890 y 1895, este interés "cosmopolita» se restringió a Bélgica, Alemania, Escandinavia, Italia y Rusia, y poco a poco se fue abriendo a otras producciones.

17. Resulta muy ilustrativa, al respecto, la mirada contemporánea, en las propias palabras de Alfred Vallette al presentar el primer número del Mercure de France, en enero de 1890, en torno a las motivaciones que podían justificar la aparición de una revista: «entre los tres fines que puede plantearse un periódico literario -ya sea ganar dinero, ya agrupar autores en comunión estética, o que conforman una misma escuela y se esmeran en el proselitismo, ya, por último, publicar obras puramente artísticas y concepciones lo suficientemente heterodoxas como para que otras hojas que poseen su clientela no las recojan- hemos elegido éste último...» (citado por Décaudin 1992, pág. 9). Como se ve, la cuestión económica coexistía junto a las preocupaciones de orden ideológico-literario por un lado, y a la búsqueda de medios de difusión de las escrituras aun desconocidas o no consagradas, por el otro. 
mirada «americana y española, pero casi universal, respecto de las novedades culturales parisinas», y especialmente por su labor de difusión de la literatura americana en Europa.

En tercer lugar, con respecto a la declarada intención de la revista de no referirse a cuestiones exclusivamente literarias, y de publicar crónicas y artículos de actualidad. ${ }^{18}$ El Nuevo Mercurio lo exponía ya en las palabras de apertura del número 1 :

Todos los asuntos que interesan a los hombres actuales, por arduos y espinosos que parezcan, serán estudiados en [la revista], pues para nosotros la intelectualidad no es, como lo cree nuestro ilustre colaborador Unamuno, un ejercicio ideológico, sino un eco palpitante del pensamiento humano. (pág. 4)

Puede leerse aquí, además, un uso polémico de los términos «intelectuales» e «intelectualidad». A su vez, recordemos que en el subtítulo que agregaba en su contraportada, la publicación se describía como «Revista mensual de Literatura, Artes, estudios sociales, etc.», propósito que se concretaba desde el primer número, con un artículo de Manuel Ugarte sobre «El porvenir de la América latina», y otro del periodista francés André Ibels sobre «La decadencia del periodismo en Francia». En el orden de la política internacional, haciendo énfasis en la cuestión de la soberanía de las jóvenes repúblicas latinoamericanas, la revista llegó a publicar los discursos de algunos de los delegados ante la conferencia de La Haya (junio a octubre de 1907) (Holguín; Luis María Drago, Pérez Triana) y una crónica de Gómez Carrillo, que defendían el arbitraje como una solución para los conflictos territoriales.

Finalmente, una variación central de la revista dentro de la tradición hispanoamericana construida en torno a las revistas de la modernización cultural, se dio en la acentuación de la universalidad del proyecto -lo que se evidenciaba en la omisión de la referencia geográfica en su mismo títuloy en una operación de acercamiento ya no entre los latinoamericanos sino entre los españoles y latinoamericanos. Así, en las palabras de apertura, el principal programa que expresaba la revista consistía en «establecer un lazo fraternal entre los intelectuales de España y de la América española, que hasta ahora han vivido no sólo desconociéndose sino desdeñándose». Ahora bien, de hecho, el acercamiento contenía un tercer eje orientado hacia Francia, lo que hacía posible la formación de un «todo homogéneo en el que los lectores encontrar[í]an no sólo un reflejo perfecto de las letras contemporáneas

18. La revista iba en el mismo sentido que había tomado el propio Mercure de France desde 1896-1897, según observó Michel Décaudin (1992, pág. 14). Esto le permitió disputar lectores a la Revue des Deux Mondes, lo que también puede pensarse para el caso de El Nuevo Mercurio habida cuenta de la circulación de esta revista en Latinoamérica. 
sino también un cuadro de las preocupaciones de nuestra época» (El Nuevo Mercurio, 1, 1907, pág. 4). Se trataba de una apertura y difusión de lo nuevo, que justificaba de este modo el cosmopolitismo. Recordemos que este tipo de operaciones aparecían, como he señalado más arriba, en la sección «Variedades y revista de revistas y periódicos». Pero tampoco impedían la existencia de voces heterógeneas respecto de la legitimidad indiscutida de los centros europeos. Esto puede verse, por ejemplo, en la nota de Pater en el número 8, seleccionada de La Nación de Buenos Aires:

Hogar común donde todas las firmas se estampan y donde todas las ideas, todas las doctrinas, todas las preocupaciones tienen cabida, suscriptas por americanos, por franceses, por italianos y por alemanes, a pocos pasos se está de definirse y conocerse lo que cada nación ha producido en las artes o en las ciencias. Creo que ése es el mejor expediente para disipar tinieblas y para combatir ignorancias.

(...) El Nuevo Mercurio, Señor Carrillo, me está enseñando cosas muy buenas, se lo juro, y es tal la importancia que le asigno, para empezar, aunque más no sea, el intercambio intelectual con varios naciones viejas y jóvenes que, o mucho me engaño, o creo que está destinado a servir de vehículo y puente a infinidad de ideas y a muchas verdades que nadie sospecha... (Pater 1907, pág. 510).

En este mismo artículo de Pater, cuya presencia en la revista ilustra la estrategia autorreferencial a la que me he referido más arriba, se advierte la incorporación de voces heterogéneas respecto de aquello que se escribía en sus propias páginas. En efecto, además de la defensa de la universalidad en la que podían tener igual cabida las producciones culturales de naciones «viejas y jóvenes», el periodista expresaba su sospecha ante la «moda de París», y aquello que los franceses decían sobre su propia cultura, destacando irónicamente el «talento del francés para hacernos tragar gato por liebre» y que «de tal manera se han arreglado para sentar dondequiera su hegemonía, que no les falta los imitadores que a veces los dejan tamañitos en lo de sorprender la fácil credulidad de las gentes» (El Nuevo Mercurio, 8, págs. 906-907).

Como efecto de este mecanismo de universalización de los debates, la actualidad, tantas veces mentada, que sostuvo la revista, circulaba en múltiples direcciones: del centro parisino a las periferias, a un lado y otro del Atlántico. Sin duda, este mecanismo de igualación intercultural había sido posible tras el impacto de las propias producciones del modernismo literario, a lo largo de los diez años anteriores. ${ }^{19}$ Así, en la sección «Nuestras artes y letras juzgadas

19. Si leemos este gesto en las claves de la emancipación intelectual que conceptualizó Jacques Rancière en El maestro ignorante, El espectador emancipado o La noche de los proletarios, quizá pueda pensarse que se trata, en este caso, de un atisbo de emancipación 
por los extranjeros» se publicaban artículos que relevaban la recepción de libros hispanoamericanos publicados en España o Francia. ${ }^{20}$ Pero además, se produce una inversión de las interpelaciones, pues desde los mismos centros europeos, la revista convocaba a las voces tanto latinoamericanas como europeas (españoles, franceses, italianos). Aquí, debe señalarse que una de las operaciones claves fue la traducción, a través de la cual se importaba la novedad cultural. Así, además de los artículos críticos aparecidos primero en otras revistas en francés, inglés italiano o portugués, que la revista traducía y publicaba en sus páginas, también traducía ficciones o fragmentos de obras teatrales de Huysmans, Hugo, Moréas, Wilde, Lajeunesse y Paul Margueritte.

En materia de poesía, en cambio, aparecían sólo voces hispanoamericanas y españolas de las últimas generaciones (a excepción, una vez más, de Unamuno y también de Salvador Rueda): José Santos Chocano, Darío, Díaz Romero, Amado Nervo, Díez-Canedo pero también Manuel Machado, Andrés González Blanco, Ramón Pérez de Ayala, entre otros poetas españoles. En estas operaciones antológicas de la revista, cabe destacar, nuevamente, el modo en que la selección respondía también a las relaciones de Gómez Carrillo pues en casi todos los casos, se trataba de poemas solicitados a poetas españoles que frecuentaba en sus estancias madrileñas, o de poetas latinoamericanos con quienes, en su mayoría, había estrechado lazos en París. De este modo también se concretaban los vínculos entre escritores de habla española de una misma generación, que se desarrollaron en el marco del movimiento modernista hispanoamericano. El análisis de El Nuevo Mercurio permite así indagar su participación en el progresivo abandono de la tradición antihispánica de las elites latinoamericanas, una línea que se continuará en otras publicaciones posteriores, también editadas en Europa como La Revista de América (1912), La Revue Sud-Américaine (1914), entre otras.

A partir de este recorrido, quisiera destacar que tanto las filiaciones trazadas por la publicación respecto de sus antecesoras como los vínculos que entabló con sus contemporáneas contribuyeron a estructurar el espacio literario y cultural latinoamericano en formación. En efecto, El Nuevo Mercurio participó de la constitución simbólica de lo Latinoamericano como área cultural

intelectual, de un destello de irrupción igualitaria dentro de la lógica de la distribución planetaria, geopolítica, de los saberes y prácticas artísticas.

20. Esta sección no apareció regularmente en todos los números, aunque sí en cinco de ellos: el n. ${ }^{\circ} 1$ apareció «Un estudio inglés sobre Queirol» (págs. 95-98); en el n. ${ }^{\circ} 2$, «Un estudio inglés sobre Sorolla», págs. 224-228); n. ${ }^{\circ} 3$, «Prólogo a El alma japonesa, obra de Gómez Carrillo, págs. 310-317); n. ${ }^{\circ} 7$, «Un artículo de Catulle Mendès sobre Terres lointaines de Gómez Carrillo», págs. 808-811); n. ${ }^{\circ} 8$ ( «Un artículo portugués sobre dos novelas hispanoamericanas», de M. de Oliveira Lima). 
específica que fue posible, tal como he intentado mostrar en este trabajo, mediante mecanismos de universalización de los debates, que tuvieron un efecto legitimador respecto de aquellas voces extranjeras que se aventuraban en la selva de la cultura europea y sus espacios de producción literaria e intelectual. Finalmente, el análisis de una práctica intelectual como la de Enrique Gómez Carrillo a través de la dirección de una revista, permite observar los modos en que se fue consolidando el oficio de escritor, proceso que tuvo aristas muy concretas detrás del cultivo de una identidad de artista despreocupado y aturdido por la velocidad de los tiempos modernos.

\section{Bibliografía}

Archivo General de la Nación, El epistolario de Manuel Ugarte, Buenos Aires, AGN, 1999.

El Nuevo Mercurio, Barcelona, Sopena, 1907.

Mercure de France, París. Año 1907.

CÁCERES, Aurora, Mi vida junto a Gómez Carrillo, Guatemala, Tipografía Nacional, 2008 [1929].

CANSINOS AsSENS, Rafel. La novela de un literato.1919.

Celma Valero, María Pilar, Literatura y periodismo en las revistas del fin de siglo. Estudio e indices (1888-1907), Madrid, Júcar, 1991.

DÉCAUdin, Michel, «Le Mercure de France: filiations et orientations», Revue d'Histoire littéraire de la France, enero-febrero, 1992, págs. 7-16.

DELGADO, Verónica, El nacimiento de la literatura argentina en las revistas literarias (1896-1913), La Plata, Edulp, 2009.

GARCía Morales, Alfonso, «Últimas batallas sobre el modernismo: la segunda Revista Azul de México», Alicante, Biblioteca Virtual Miguel de Cervantes, 2010. http://www.cervantesvirtual.com/obra-visor/ultimas-batallas-sobreel-modernismo-la-segunda-revista-azul-de-mexico-0/html/d00816ba-25de4097-9d42-ada93fc61419_6.html. Consultado el 18/07/2014.

GHIRALDO, Alberto, El archivo de Rubén Darío, Santiago de Chile, Ed. Bolívar, 1940.

Gómez Carrillo, Enrique. Carta de Gómez Carrillo a Miguel de Unamuno (manuscrita) [1906]. www.gredos.usal.es

Gómez CARRILlo, Enrique, 1907a, «Lettres espagnoles», Mercure de France, $1 .{ }^{\circ}$ de marzo de 1907, págs. 180-183.

[Gómez CARRILlo, Enrique], 1907b, «Un artículo del Mercure de France sobre El Nuevo Mercurio», El Nuevo Mercurio, 5, mayo de 1907, pág. 577.

GonZÁlez MARTel, Juan Manuel, Enrique Gómez Carrillo, cronista y director de publicaciones periódicas, Guatemala, Editorial Oscar de León Palacios, 2005. 
JimÉNEZ AGUiRRE, Gustavo Humberto, «Estela intercontinental de El Nuevo Mercurio (1907)», en Regina Crespo (coord.), Revistas en América Latina: proyectos literarios, políticos y culturales, México, UNAM/Ediciones Eón, 2010.

JOUANNY, Robert, «Les orientations étrangères au Mercure de France (1890-1895)». Revue d'Histoire littéraire de la France, enero-febrero1992, págs. 56-72.

MERBILHAÁ, Margarita, «Emergencias de la mediación intelectual. La Revista de América (París, 1912-1914) y la red de escritores latinoamericanos en Europa a comienzos del siglo XX». Ponencia presentada en el «I Coloquio regional de la SHARP A Cidade das Letras». Universidad Federal Fluminense, Rio de Janeiro, noviembre de 2013.

MolLier, Jean-Yves, «La revue dans le système editorial», en Jacqueline PluetDespatin, Michel Leymarie y Jean-Yves Mollier (dir.), La Belle Époque des revues, Paris, Éd. de l'IMEC, 2002, págs. 43-55.

Molloy, Sylvia, La diffusion de la littérature hispano-américaine en France au XXe siècle, Paris, PUF, 1972.

SERRANO, Carlos, «Les revues littéraires dans l'Espagne fin-de-siècle», en Jacqueline Pluet-Despatin, Michel Leymarie y Jean-Yves Mollier (dir.), La Belle Époque des revues, Paris, Éd. de l'IMEC, 2002, págs. 385-396.

NoGUEROL, Francisca, «'Soñadores de las mismas quimeras'. Enrique Gómez Carrillo y la revista Cosmópolis (1919-1922)», en Carmen de Mora y Alfonso García Morales (eds.), Viajeros, diplomáticos y exiliados. Escritores hispanoamericanos en España (1914-1939), Vol. I, Bruxelles, P.I.E Peter Lang, 2012, págs. 353-369.

Pater [Roberto G. Paterson], «El Nuevo Mercurio en América», El Nuevo Mercurio 8, 1907, págs. 905-912.

UnAmuno, Miguel de, «Poesía y Arte», El Nuevo Mercurio 1, enero 1907, págs. $12-15$.

Zegers, Pedro y Harris, Thomas, Rubén Darío, epistolario selecto, Santiago de Chile, Dibam/LOM Ediciones, 1999.

ZulETA, Ignacio, «El Nuevo Mercurio (1907)», Inter-American Review of Bibliography, Washington, XXXI, 3, 1981, págs. 385-403.

Fecha de recepción: 20/08/2014

Fecha de aceptación: 01/10/2014 